\title{
Statistical study of the DP2 enhancement at the dayside dip-equator compared to low latitudes
}

\author{
N. M. Mene ${ }^{1}$, A. T. Kobea ${ }^{1}$, O. K. Obrou ${ }^{1}$, K. Z. Zaka ${ }^{1}$, K. Boka ${ }^{1}$, C. Amory-Mazaudier ${ }^{2}$, and P. Assamoi ${ }^{1}$ \\ ${ }^{1}$ Laboratoire de Physique de l'Atmosphère, Université de Cocody, 22 BP 582 Abidjan 22, Côte d'Ivoire \\ ${ }^{2}$ Laboratoire de Physique des Plasmas, CNRS, UPMC 4 avenue de Neptune 94107 Saint-Maur-des-Fossés, France
}

Received: 5 March 2011 - Revised: 19 July 2011 - Accepted: 22 November 2011 - Published: 6 December 2011

\begin{abstract}
It has been largely investigated and established that the DP2 events are enhanced at dip-equator compared to low latitudes. Studies by several authors showed various enhancement ratio values of DP2 amplitude at the dayside dipequator relative to those at low latitudes. In order to quantify this enhancement ratio, we carried out a statistical study on this phenomenon using the ground magnetometer data at locations ranging from polar cap to dip-equator over the African, Asian and American sector. Our result gave an enhancement ratio which shows a diurnal variation with a maximum value around 12:00 LT and is correlated with the regular variation of the geomagnetic H-component. The longitudinal variation of the enhancement ratio of the DP2 exhibits high values over the American sector compared to Asian sector and African sector which have lowest values. This longitudinal dependence is similar to that of the equatorial electrojet magnetic effect.
\end{abstract}

Keywords. Magnetospheric physics (Magnetosphereionosphere interactions)

\section{Introduction}

The geomagnetic disturbances observed generally at low latitudes are attributed to the magnetospheric electric fields and currents that connect the high-latitude ionosphere with the low-latitude ionosphere penetrating through the middle latitude (Nishida et al., 1966; Reddy et al., 1979; Kikuchi et al., 1996; Kobea et al., 1998). Studies by Nishida et al. (1966) found that a type of disturbance called DP2, is associated with fluctuations in north-south component of interplanetary magnetic field. The DP2 events are characterized by magnetic fluctuations with periods of 30 to $60 \mathrm{~min}$ at

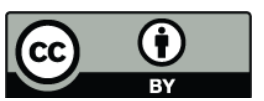

Correspondence to: N. M. Mene (medardmene@yahoo.fr) low latitudes (Nishida, 1979). These events exhibit a strong decrease in magnitude with decreasing latitude, however, it is enhanced considerably at the dip-equator (Kikuchi et al., 1996). In fact the DP2 events are caused by the penetration of magnetospheric electric field at low-latitude and are affected by the redistribution of hot plasma that is the region- 2 field-aligned currents into and out of the ionosphere (Vasyliunas, 1972; Senior and Blanc, 1984; Fejer, 1979). Under steady state conditions these region-2 currents tend to minimize the penetration of ionospheric electric fields and currents between the auroral region and low-latitude, producing a shielding electric field (Karlson, 1979; Block, 1979; Vasyliunas, 1972; Southwood, 1979). During time-varying disturbances, the distribution of magnetospheric plasma and the accompanying shielding currents do not have the time to develop the appropriate shielding electric field. The magnetospheric electric field therefore can penetrate at the mid-, lowand equatorial latitude ionosphere (Jaggi and Wolf, 1973; Kelley et al., 1979; Spiro et al., 1988; Fejer et al., 1990; Sobral et al., 2001; Abdu et al., 1998). This penetration causes the DP2 events. It has been largely investigated and established that the DP2 magnetic fluctuations were enhanced in amplitude at the dayside dip-equator compared to those at low latitude (Kikuchi et al., 2008; Nishida, 1971). Studies by Kobéa et al. (2000) and Kikuchi et al. (2008) reported DP2 amplitude enhancement factors of about 4 and 2.7 respectively. These results show variation in DP2 enhancement ratio and efforts must be made towards having a good understanding of the DP2 events at the equator in order to improve the modeling of this phenomenon. The DP2 enhancement at the dip-equator is caused by the high values of the Cowling conductivity at low latitudes, responsible for the equatorial electrojet (EEJ) circulation having the regular variation of geomagnetic H-component $\left(S_{\mathrm{r}}(H)\right)$ as its signature (Fambitakoye and Mayaud, 1976a; Baker and Martyn, 1953; Hirono, 1952). So, the DP2 enhancement ratio should present a diurnal variation which can be estimated by the

Published by Copernicus Publications on behalf of the European Geosciences Union. 
Table 1. Locations of magnetic stations.

\begin{tabular}{|c|c|c|c|c|c|c|}
\hline \multirow[t]{2}{*}{ Code } & \multirow[t]{2}{*}{ Name } & \multicolumn{2}{|c|}{ Geo. coordinates } & \multicolumn{2}{|c|}{ Mag. coordinates } & \multirow{2}{*}{$\begin{array}{l}\text { Local } \\
\text { time }\end{array}$} \\
\hline & & Latitude & Longitude & Latitude & longitude & \\
\hline & Polar cap & & & & & \\
\hline ALE & Alert & 82.50 & -62.35 & 86.89 & 168.2 & $\mathrm{UT}-4.1$ \\
\hline \multirow[t]{2}{*}{ RES } & Resolute Bay & 74.69 & -94.89 & 82.90 & -70.70 & $\mathrm{UT}-6.3$ \\
\hline & African sector & & & & & \\
\hline $\mathrm{ABK}$ & Abisko & 68.36 & 18.82 & 66.06 & 114.66 & $\mathrm{UT}+1.2$ \\
\hline LOV & LOVO & 59.34 & 17.82 & 62.37 & 106.36 & $\mathrm{UT}+1.1$ \\
\hline FUR & Furstenfeldbruck & 48.17 & 11.28 & 48.40 & 94.61 & $\mathrm{UT}+0.7$ \\
\hline TAM & Tamanrasset & 22.79 & 5.53 & 24.66 & 80.31 & $\mathrm{UT}+0.3$ \\
\hline MOP & Mopti & 14.51 & 355.91 & 3.85 & 69.90 & $\mathrm{UT}-0.2$ \\
\hline NIE & Niellé & 10.20 & -05.64 & -00.89 & 67.88 & $\mathrm{UT}-0.3$ \\
\hline \multirow[t]{2}{*}{ AAE } & Addis Abeba & 09.3 & 38.76 & 00.18 & 11,80 & $\mathrm{UT}+2.5$ \\
\hline & American sector & & & & & \\
\hline IQA & Iqaluit & 63.75 & -68.52 & 73.98 & 05.96 & $\mathrm{UT}-4.5$ \\
\hline FRK & Fredericksburg & 38.20 & -77.37 & 48.40 & -06.17 & UT -5.1 \\
\hline SJG & San Jan & 18.11 & -66.15 & 28.31 & -03.60 & $\mathrm{UT}-4.4$ \\
\hline \multirow[t]{2}{*}{ HUA } & Huancayo & -12.04 & -75.32 & -1.8 & -3.15 & $\mathrm{UT}-5.0$ \\
\hline & Asian sector & & & & & \\
\hline CSY & Casey & -66.28 & 110.53 & -80.40 & -178.01 & $\mathrm{UT}+7.33$ \\
\hline IRT & Irkutsk & 52.27 & 104.27 & 41.93 & 175.20 & $\mathrm{UT}+6.9$ \\
\hline HTY & Hatizyo & 33.07 & 139.82 & 24.20 & -151.22 & $\mathrm{UT}+9.2$ \\
\hline YAP & Yap & 09.30 & 138.50 & -00.3 & -151.00 & $\mathrm{UT}+9.2$ \\
\hline
\end{tabular}

$S_{\mathrm{r}}(H)$ values. The purpose of the present paper is to study the diurnal and longitudinal variation of DP2 enhancement ratio at the dayside dip-equator relative to those at low latitudes and to show the correlation between the enhancement ratio and the $S_{\mathrm{r}}(H)$ values. Section 2 presents the data used and the method of analysis. Section 3 is devoted to the presentation of DP2 disturbances during the 11 March 1993 magnetic storm. In Sect. 4, we carry out the study of the latitudinal profile of DP2 magnetic fluctuations which occurred during the 11 March 1993 magnetic storm. Section 5 deals with a statistical study that shows the diurnal variation of DP2 enhancement average ratio and its correlation with the $S_{\mathrm{r}}(H)$ variation. Section 6 presents the longitudinal dependence of the DP2 enhancement ratio. Section 7 is the summary and conclusion.

\section{The data used and the method of analysis}

We use ground-based magnetometers data recorded at high, mid and low latitudes over the American, African and Asian longitude sectors. The geographic and the geomagnetic coordinates of the magnetometer stations are listed in Table 1. Data from those three sectors are geomagnetic minute values. The selected storm days are given in Tables 2 and 3 . The times mentioned on these tables are the times of the beginning of DP2 disturbances. In order to investigate the DP2 events, we use Dst, AU, AL indices and the horizontal com- ponent of geomagnetic field $H$. The Dst index gives an estimate of the sum of magnetospheric currents and depicts the different phases of magnetospheric disturbances (Akasofu, 1964). In fact, it illustrates the magnetic effects of the Chapman Ferraro currents (DCF), the ring current (DR) and the tail current (DT) during the magnetic storm. The AU and AL indices are used to evaluate the auroral electrojets currents amplitude and the arrival of magnetospheric particles in the high latitudes ionosphere. The $\mathrm{H}$ component gives an estimate of the equatorial electrojet current intensity; it should be noted that it integrates the effects of all currents flowing in the Earth's environment. These effects can be gathered in two folds: the daily local time variation of the Earth's magnetic field during quiet days $\left(S_{\mathrm{r}}\right)$ and the disturbed variation $(D)$ due to the electric currents generated by the various disturbance mechanisms. The DP2 events are generally observed during the main phase of the magnetic storm (Huang et al., 1979). During this period, DCF, DT and DG are negligible and only the ring current (DR) in the magnetosphere is intense (Cole, 1966; Fukushima and Kamide, 1973) and is evaluated by the Dst index which gives a good approximation of the symmetric ring current. We may infer the magnetic disturbance DP (Disturbed Polar) that represents the magnetic effects of the ionospheric electric current systems; generated by the penetration of magnetospheric convection electric field at equator (DP2) and the ionospheric disturbance dynamo (Ddyn) as follows: 
Table 2. Magnetic storms days selected in 1993 and times of the beginning of DP2 disturbances at Niellé (NIE) over African sector.

\begin{tabular}{lll}
\hline Dates & $\Sigma K p$ & Times of the beginning of DP2 disturbances (LT) \\
\hline 25 January 1993 & 18 & $08: 30 ; 09: 00 ; 09: 45 ; 11: 00 ; 11: 30$ \\
7 February 1993 & $30-$ & $08: 15 ; 09: 20 ; 12: 45 ; 13: 45 ; 18: 30$ \\
17 February 1993 & $30+$ & $08: 00 ; 12: 15 ; 13: 30$ \\
11 March 1993 & $36-$ & $09: 45 ; 12: 30 ; 14: 15 ; 17: 45$ \\
23 March 1993 & $19+$ & $08: 40 ; 10: 15 ; 11: 30$ \\
5 April 1993 & $47+$ & $12: 00 ; 14: 00 ; 18: 10 ; 18: 30$ \\
12 April 1993 & $19+$ & $08: 15 ; 09: 00 ; 10: 12 ; 10: 30 ; 11: 15 ; 13: 00 ;$ \\
& & $13: 15 ; 14: 00 ; 16: 15$ \\
27 May 1993 & $26-$ & $11: 45 ; 12: 30 ; 12: 50 ; 13: 30 ; 14: 15 ; 15: 00 ;$ \\
& & $15: 30 ; 16: 30 ; 17: 30 ; 18: 00$ \\
3 June 1993 & 23 & $09: 10 ; 10: 50$ \\
24 September 1993 & $48+$ & $07: 30 ; 08: 00 ; 09: 00 ; 10: 05 ; 11: 30 ; 12: 15 ;$ \\
& & $13: 00 ; 14: 00$ \\
9 October 1993 & $38-$ & $08: 5 ; 08: 45 ; 09: 15 ; 09: 42 ; 11: 30$ \\
25 October 1993 & $31+$ & $06: 45 ; 07: 15 ; 07: 30 ; 10: 00 ; 11: 00 ; 13: 00 ;$ \\
& & $15: 00 ; 16: 45 ; 18: 10$ \\
4 November 1993 & 47 & $06: 15 ; 07: 15 ; 07: 45 ; 08: 15 ; 09: 00 ; 10: 00 ;$ \\
& & $11: 45 ; 14: 00 ; 16: 30 ; 18: 15$ \\
18 November 1993 & $27-$ & $12: 00 ; 14: 00 ; 16: 05 ; 18: 00$
\end{tabular}

Table 3a. Magnetic storms days selected of 1998 and times of the beginning of DP2 disturbances at Addis Ababa (AAE) over African sector.

\begin{tabular}{lll}
\hline & \multicolumn{2}{c}{ African sector } \\
\hline Dates & $\Sigma$ Kp & Times of the beginning of DP2 disturbances (LT) \\
\hline 31 January 1998 & $15+$ & $11: 30 ; 16: 40$ \\
17 February 1998 & 19 & $15: 00 ; 17: 00 ; 19: 15$ \\
10 March 1998 & 35 & $06: 30 ; 07: 15 ; 08: 20 ; 10: 10 ; 12: 20 ; 18: 00$ \\
2 May 1998 & $43-$ & $09: 00 ; 11: 00 ; 13: 00 ; 15: 15 ; 17: 10$ \\
26 June 1998 & $34+$ & $06: 30 ; 07: 15 ; 11: 00 ; 12: 15 ; 13: 05 ; 14: 00$ \\
16 July 1998 & $35+$ & $07: 00 ; 08: 00,08: 45 ; 10: 45 ; 15: 15 ; 16: 50 ;$ \\
& & $17: 30$ \\
6 August 1998 & 39 & $06: 30 ; 08: 25 ; 10: 20$ \\
27 August 1998 & 57 & $13: 25 ; 15: 45 ; 17: 00$ \\
18 September 1998 & $28-$ & $08: 45 ; 11: 00 ; 18: 00$ \\
25 September 1998 & 48 & $06: 30 ; 07: 15 ; 07: 45 ; 08: 30 ; 13: 15 ; 16: 00$ \\
7 October 1998 & $29+$ & $08: 25 ; 09: 30 ; 14: 30 ; 16: 00 ; 18: 00$ \\
19 October 1998 & $43-$ & $14: 20 ; 15: 00 ; 15: 45 ; 17: 40$ \\
13 November 1998 & 44 & $06: 10 ; 07: 00 ; 08: 30 ; 10: 00 ; 11: 15 ; 12: 20 ;$ \\
& & $13: 00 ; 14: 30 ; 17: 00$ \\
26 December 1998 & $23-$ & $12: 00 ; 13: 45 ; 15: 10 ; 16: 45$ \\
\hline
\end{tabular}

$\mathrm{DP}=H-\mathrm{Dst} \times \cos (L)-S_{\mathrm{r}}$

Where $L$ is the geomagnetic latitude of the station and $S_{\mathrm{r}}$ is the average of the five quietest days of the month. The DP2 events are characterized by coherently variations of the DP from high latitude to dip-equator (Kobéa et al., 2000).

\section{DP2 disturbances during the magnetic storm of 11 March 1993}

\subsection{Definition}

Geomagnetic storm-time variations often show magnetic fluctuations occurring coherently at high latitude on the dayside dip-equator where they affect the regular variations (Onwumechilli et al., 1973; Nishida et al., 1966). Those magnetic fluctuations called DP2 caused by the alternating 
Table 3b. Magnetic storms days selected of 1998 and times of the beginning of DP2 disturbances at Huancayo (HUA) over American sector.

\begin{tabular}{lll}
\hline & \multicolumn{3}{c}{ American sector } \\
\hline Dates & $\Sigma$ Kp & Times of the beginning of DP2 disturbances (LT) \\
\hline 6 January 1998 & $23+$ & $09: 05 ; 10: 25 ; 11: 00 ; 11: 30 ; 13: 00 ; 15: 30 ;$ \\
16:20; 18:25; 18:50 & & \\
17 February 1998 & 19 & $10: 30 ; 11: 15 ; 12: 00 ; 13: 00 ; 13: 35 ; 15: 45 ;$ \\
16:30; 17:15;18:00; 18:45 & & \\
10 March 1998 & 35 & $06: 30 ; 07: 00 ; 08: 45 ; 09: 30 ; 10: 15 ; 11: 00 ;$ \\
& & $12: 15 ; 12: 30 ; 14: 00$ \\
20 March 1998 & 16 & $05: 20 ; 07: 15 ; 07: 45 ; 08: 30 ; 10: 00$ \\
21 March 1998 & $30+$ & $07: 30 ; 08: 15 ; 09: 00 ; 09: 35 ; 13: 00 ; 13: 40 ;$ \\
& & $14: 30 ; 15: 30$ \\
24 April 1998 & $16+$ & $13: 50 ; 16: 00 ; 16: 30 ; 17: 15$ \\
6 August 1998 & 39 & $04: 30 ; 06: 20 ; 07: 00$ \\
26 August 1998 & 57 & $05: 15 ; 06: 10 ; 09: 30 ; 11: 15 ; 12: 40 ; 18: 38$ \\
27 August 1998 & 57 & $05: 20 ; 06: 10 ; 07: 15 ; 07: 45 ; 09: 00 ; 10: 00 ;$ \\
& & $11: 30 ; 12: 20 ; 13: 30 ; 14: 30 ; 15: 30$ \\
18 September 1998 & $28-$ & $05: 20 ; 06: 10 ; 07: 00 ; 08: 10 ; 09: 30 ; 10: 10 ;$ \\
& & $11: 00 ; 12: 20 ; 13: 15 ; 14: 30$ \\
7 October 1998 & $29+$ & $07: 00 ; 08: 15 ; 09: 15 ; 09: 45 ; 11: 15 ; 13: 15$ \\
13 November 1998 & 44 & $05: 15 ; 07: 00 ; 10: 30 ; 11: 40 ; 13: 20 ; 17: 30$ \\
\hline
\end{tabular}

Table 3c. Magnetic storms days selected of 1998 and times of the beginning of DP2 disturbances at Yap (YAP) over Asian sector.

\begin{tabular}{lll}
\hline & \multicolumn{2}{c}{ Asian sector } \\
\hline Dates & $\Sigma$ Kp & Times of the beginning of DP2 disturbances (LT) \\
\hline 7 August 1998 & 39 & $10: 30 ; 11: 10 ; 12: 45 ; 16: 00 ; 17: 45$ \\
20 August 1998 & $25+$ & $11: 20 ; 13: 00 ; 15: 15 ; 15: 35 ; 16: 40$ \\
28 August 1998 & 57 & $07: 00 ; 08: 00 ; 09: 00$ \\
18 September 1998 & $28-$ & $06: 40 ; 07: 50 ; 09: 00 ; 12: 00 ; 14: 00 ; 15: 05 ;$ \\
& & $16: 30 ; 17: 15$ \\
26 September 1998 & $24-$ & $06: 15 ; 07: 20 ; 12: 30 ; 14: 25 ; 15: 15 ; 16: 45 ;$ \\
& & $17: 00 ; 17: 45 ; 18: 25$ \\
3 October 1998 & 19 & $09: 05 ; 10: 00 ; 10: 20 ; 11: 45$ \\
8 October 1998 & $29+$ & $05: 45 ; 12: 00 ; 16: 20 ; 18: 15$ \\
20 October 1998 & $43-$ & $06: 00 ; 06: 45 ; 07: 50 ; 09: 55 ; 11: 00 ; 11: 25 ;$ \\
& & $14: 20 ; 15: 00$ \\
6 November 1998 & $27+$ & $08: 10 ; 08: 45 ; 09: 50,11: 15$ \\
13 November 1998 & 44 & $10: 00 ; 11: 30,12: 45 ; 13: 35,14: 00$ \\
14 November 1998 & 44 & $13: 30 ; 15: 10 ; 16: 45 ; 17: 40 ; 18: 20$ \\
26 December 1998 & $23-$ & $10: 40 ; 12: 00 ; 14: 00 ; 16: 00$ \\
\hline
\end{tabular}

domination of R1 and R2 FACs transmit the magnetospheric convection electric field to high latitudes ionosphere (Kikuchi et al., 1996). The time signature of DP2 fluctuations is a period of 30-60 min (Nishida, 1979) and these fluctuations continuous for several hours during the main phase of magnetic storms (Kikuchi et al., 2010). The main characteristics of the DP2 events are a falloff in amplitude with decreasing latitude and an enhancement of their amplitude on the dayside dip-equator compared to those of low latitudes (Kikuchi et al., 1996, 2000). In the following section we present some DP2 disturbances and their enhancement at dip-equator during the magnetic storm of 11 March 1993.

\subsection{DP2 disturbances during the magnetic storm of 11 March 1993}

The equatorial Dst time-variations (Fig. 1a) shows that the storm started on 11 March 1993 at 01:00 UT with a low compression phase $(+20 \mathrm{nT})$ that ended at 09:00 UT. This period is followed by the main phase of the storm characterized by 


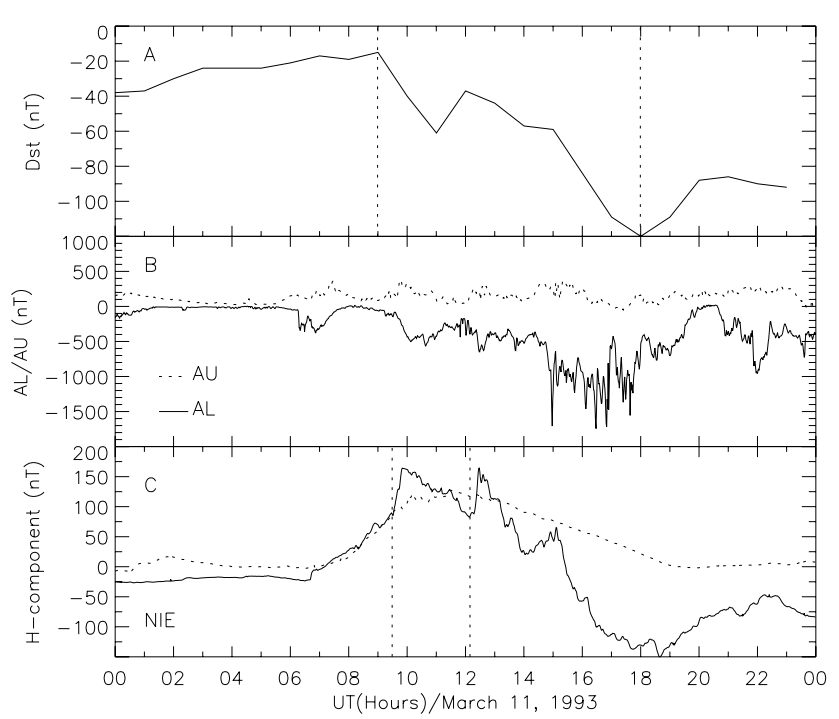

Fig. 1. Variation of the Dst index (A), the auroral indices $A L$ and AU (B) and the geomagnetic H-component (C) on 11 March 1993 (solid line). The dotted line $(\mathbf{C})$ shows the quiet time variation $\left(S_{\mathrm{r}}(H)\right)$ on 5 March 1993 (reference quiet days).

the decrease of the Dst that peaked at a value of $-120 \mathrm{nT}$ at 18:00 UT followed by the recovery phase. Figure $1 \mathrm{~b}$ shows the plot of the auroral AU, AL indices; we note an intense auroral activity on 11 March 1993 indicating the occurrence of an important magnetospheric convection process during this time period. Figure 1c shows the geomagnetic $\mathrm{H}$ component variations at Niellé (NIE) located on the dayside during the disturbed time, overlaid in a dotted line by those of the reference quiet day, that is, 5 March 1993. During the main phase of the storm, we note that the $\mathrm{H}$ component variation tracks the Dst because Nielle (NIE) is located at the dip-equator where the ring current (DR) effect is preponderant. However, appreciable increases in H component are clearly observed between 09:00 and 10:00 UT, at 12:00 and 13:00 UT while the Dst is decreasing. Figure 2 shows the DP latitudinal variations which exhibit nearly coherent increase at all stations (from polar cap to dip-equator) during the time interval 09:30-09:54 UT and 12:15-12:30 UT. These disturbances present a decrease in magnitude with decreasing latitude and an enhancement at dip-equator compared to low latitude. According Nishida (1971), these observations are the characteristics of the influence of a penetration of magnetospheric convection electric field effects at low latitude (DP2). Therefore, the $\mathrm{H}$ component disturbances observed around 09:30 and 12:15 UT depict the DP2 disturbances. When we compare DP2 amplitudes obtained by connecting the minimum value to the maximum value of the disturbance at Tamanrasset (TAM) (45 nT at 09:45 UT and $25 \mathrm{nT}$ at 12:15 UT) with those of Niellé (NIE) (82 nT at 09:45 UT and $75 \mathrm{nT}$ at 12:15 UT), we have an enhancement of DP2 disturbances at the dip-equator (Niellé) compared to

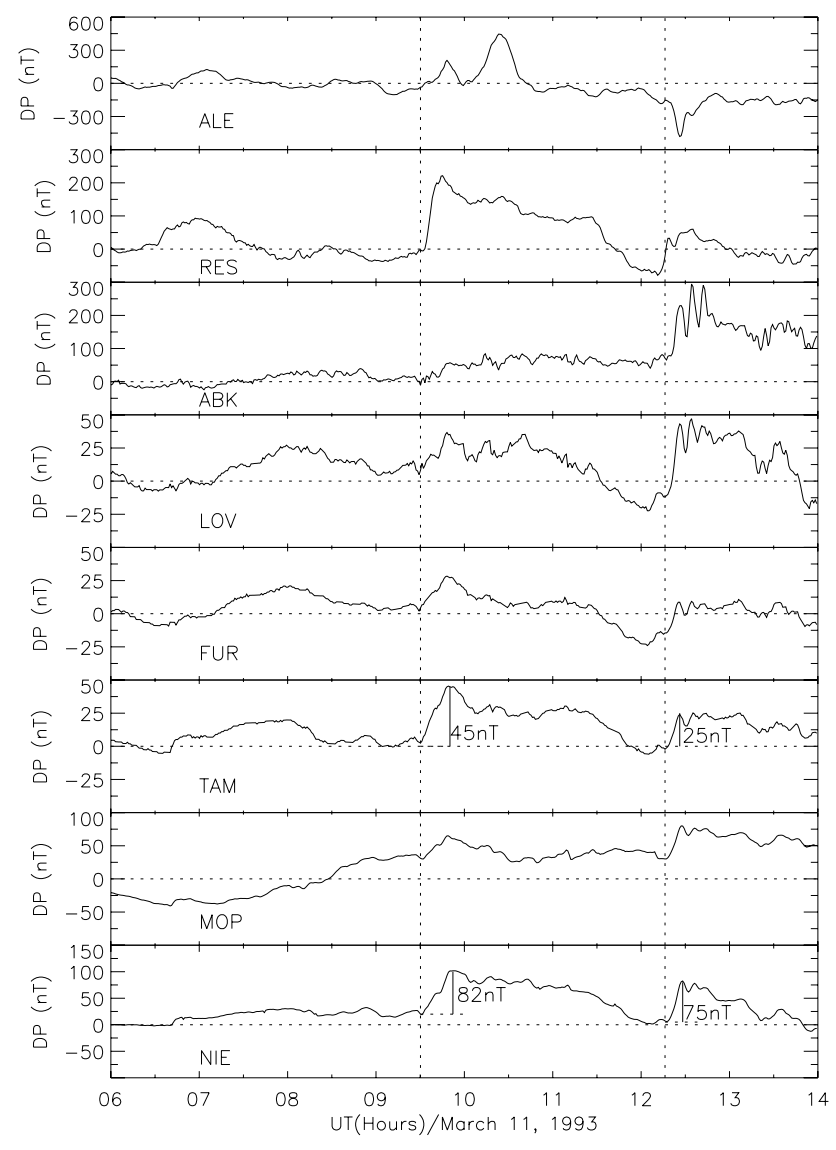

Fig. 2. Variation of H-component disturbances (DP) at polar cap (ALE, RES), high latitude (ABK, LOV), middle latitude (FUR), low latitude (TAM, MOP) and dip-equator (NIE).

the low latitudes (Tamanrasset). These enhancements detected successively at Mopti (MOP) and Niellé (NIE) confirm the circulation of currents in the equatorial ionosphere.

\section{Latitudinal profiles of DP2 events}

The latitudinal profile of the DP2 is characterized by a rapid falloff in amplitude with decreasing latitude toward the low latitude and the amplitude increase at the dip-equator due to the Cowling conductivity effect (Hirono, 1952; Kikuchi et al., 1996, 2000). Figure 3 shows the latitudinal profiles of the DP2 events on 11 March 1993 at 09:45 UT and 12:15 UT. The enhancement ratio (the DP2 amplitude at the dip-equator (Niellé) divided by that at low latitude (Tamanrasset)) obtained is 1.82 at 09:45 UT and 3 at 12:15 UT. We note that the DP2 enhancement depends on the local time. In order to show evidence of this dependence, we carried out a statistical study of several magnetic storms in 1993. Table 2 gives the analyzed magnetic storm events and the DP2 time of occurrences. 


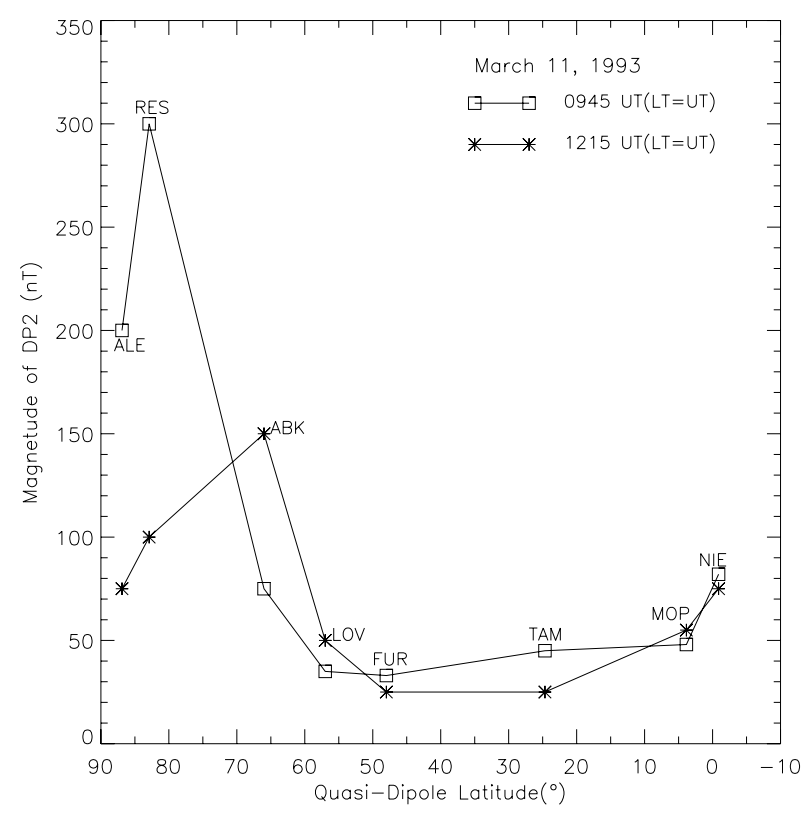

Fig. 3. Latitudinal profiles of DP2 disturbance on 11 March at 09:45 UT and 12:15 UT.

\section{Statistical study of the DP2 enhancement ratio}

\subsection{Diurnal variation of DP2 enhancement ratio}

In order to carry out the statistical study of the DP2 disturbances, we have considered the amplification factors in the time interval of an hour represented by the mid value (for example 12:00 LT represents the time interval (11:30 LT, 12:30 LT). The average of the DP2 enhancement ratio for each time interval is then calculated and plotted versus the local time on Fig. 4. During the nighttime ([00:00; 06:00 LT] and [20:00, 00:00 LT]), the DP2 amplitude is not enhanced at the dip-equator because the Cowling conductivity is weak during these time periods. During the daytime, the DP2 enhancement at the dip-equator starts around 07:00 LT with an average ratio of 1.2 ; it increases until a maximum average ratio of 3.3 around 12:00 LT and decreases, ending at 19:00 LT. The observed standard deviations can be related to the equatorial electrojet variability.

\subsection{Correlation between the DP2 enhancement ratio and $H$ component regular variation $\left(S_{\mathrm{r}}(H)\right)$}

The DP2 enhancement owing to the Cowling conductivity effects can be noticeable throughout the variation of the geomagnetic $\mathrm{H}$ component $\left(S_{\mathrm{r}}(H)\right)$ which is typical of the equatorial electrojet (Fambitakoye and Mayaud, 1976a,b). Therefore, the DP2 enhancement ratio can be estimated by the $\mathrm{H}$ component regular value. Figure 5 shows the reference days average $S_{\mathrm{r}}(H)$ values (dashed line) and the DP2 enhancement ratio at dip-equator (Niellé). The $S_{\mathrm{r}}(H)$ variation and

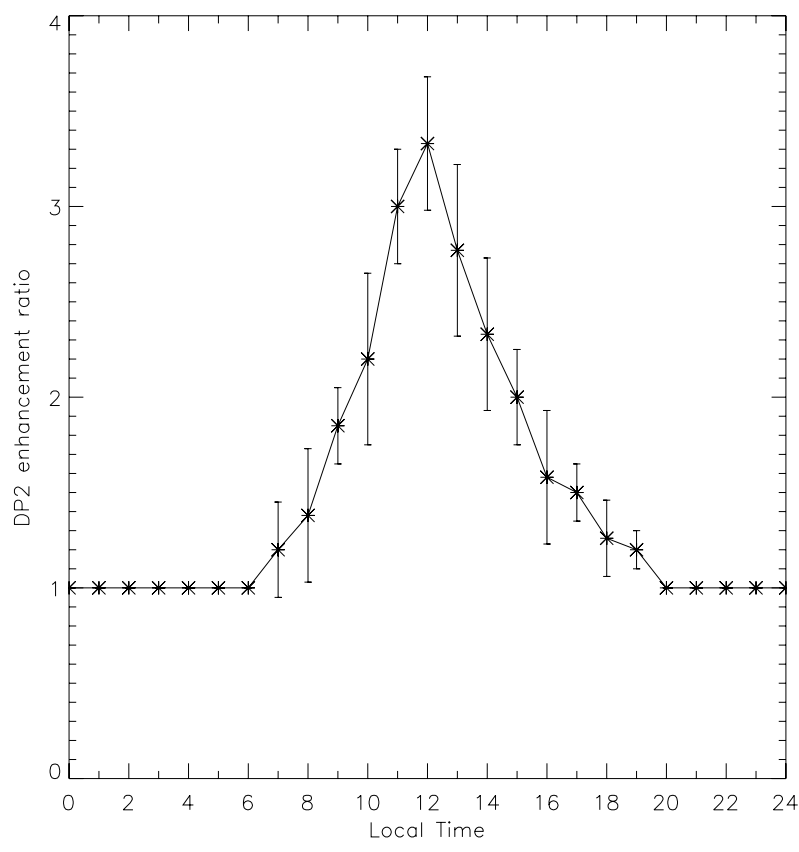

Fig. 4. Diurnal variation of DP2 enhancement ratio average in 1993 at dip-equator (NIE) compared to low latitude (TAM).

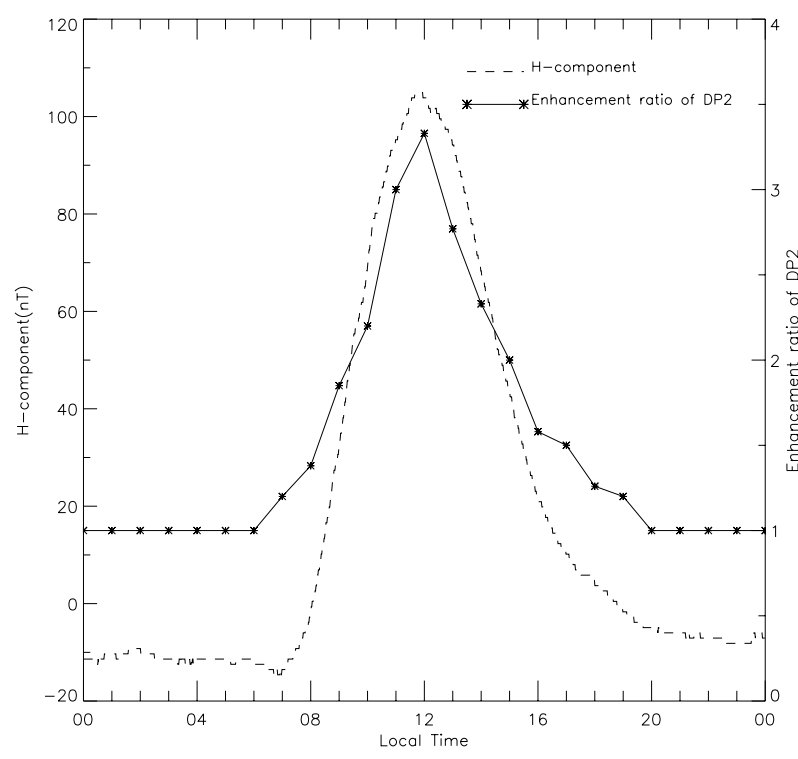

Fig. 5. African sector, results of the year 1993: Variation of DP2 enhancement ratio average at NIE (solid line) and the $S_{\mathrm{r}}(H)$ average (dotted line). The correlation coefficient is 0.95 .

the DP2 enhancement exhibit a good correlation with a value of 0.95 on the dayside [06:00-20:00 LT]. 
Table 4. DP2 amplitudes at low latitude and the equator and the enhancement ratio of DP2 between the dip-equator and the low latitude over the American, African and Asian longitude sectors.

\begin{tabular}{lccc}
\hline & American sector & African sector & Asian sector \\
& 7 October 1998 & 10 March 1998 & 19 October 1998 \\
\hline Dip-equator & Huancayo & Addis-Ababa & YAP \\
& $195 \mathrm{nT}$ & $100 \mathrm{nT}$ & $92 \mathrm{nT}$ \\
Low latitude & San Juan & Tamanrasset & Hatizyo \\
& $22 \mathrm{nT}$ & $26 \mathrm{nT}$ & $15 \mathrm{nT}$ \\
Enhancement ratio & 8.86 & 3.84 & 6.13 \\
\hline
\end{tabular}
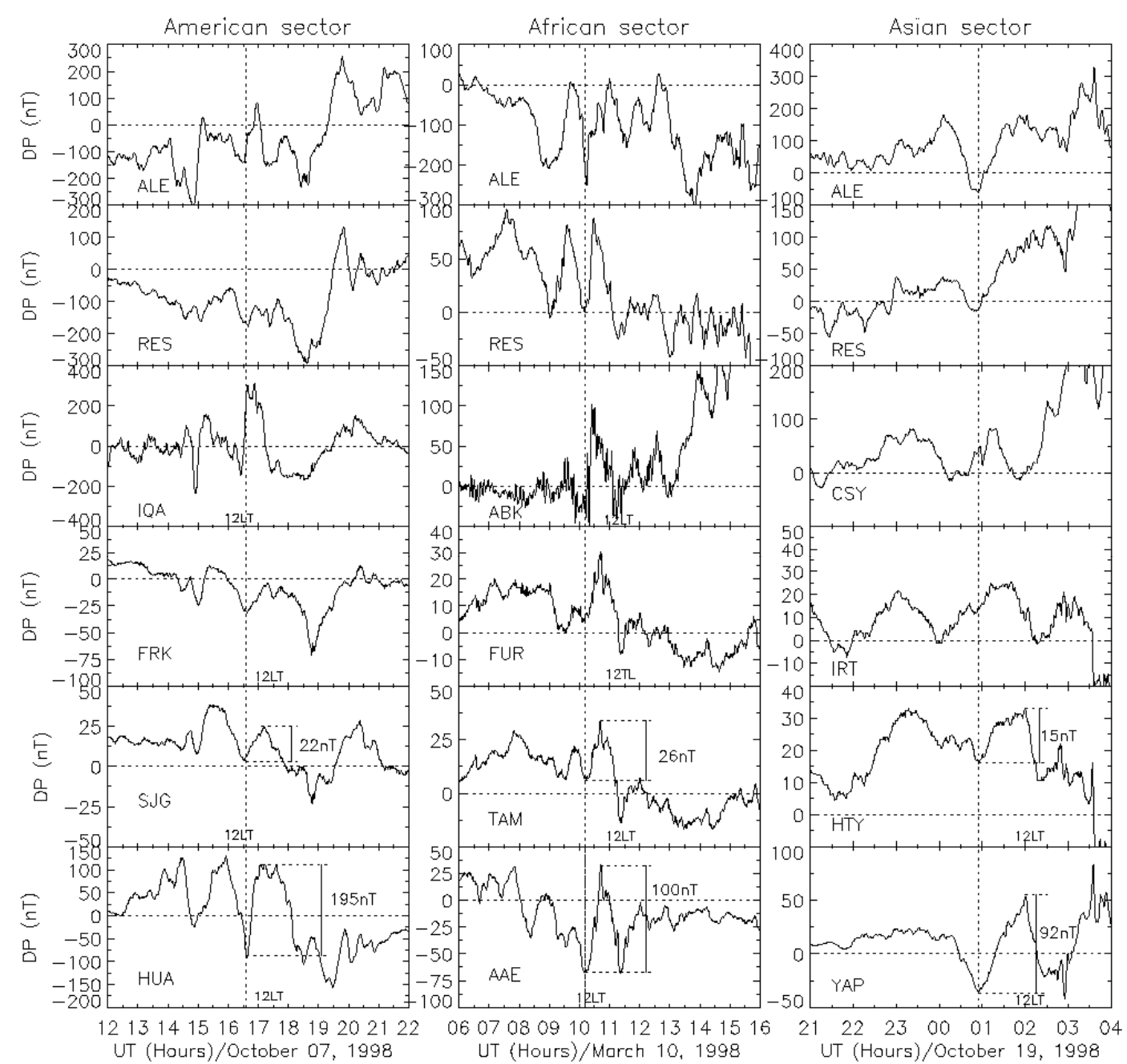

Fig. 6. Variation of H-component disturbance (DP) from high latitude to dip-equator on 7 October 1998 (American sector), 10 March 1998 (African sector) and 19 October 1998 (Asian sector).

\section{Longitudinal dependence of the DP2 enhancement ra- tio at the dip-equator}

The selected magnetic storm days with the times of the beginning of their DP2 events are given on Table $3 a, b$ and $\mathrm{c}$ for the African, American and Asian sectors respectively.
As the DP2 enhancement ratio depends on local time, we did select different DP2 disturbances occurring in the same local time i.e. 12:00 LT over the American sector (7 October 1998), the African sector (10 March 1998) and the Asian sector (19 October 1998) to illustrate the longitudinal dependence of DP2 enhancement ratio. Figure 6 presents the time 


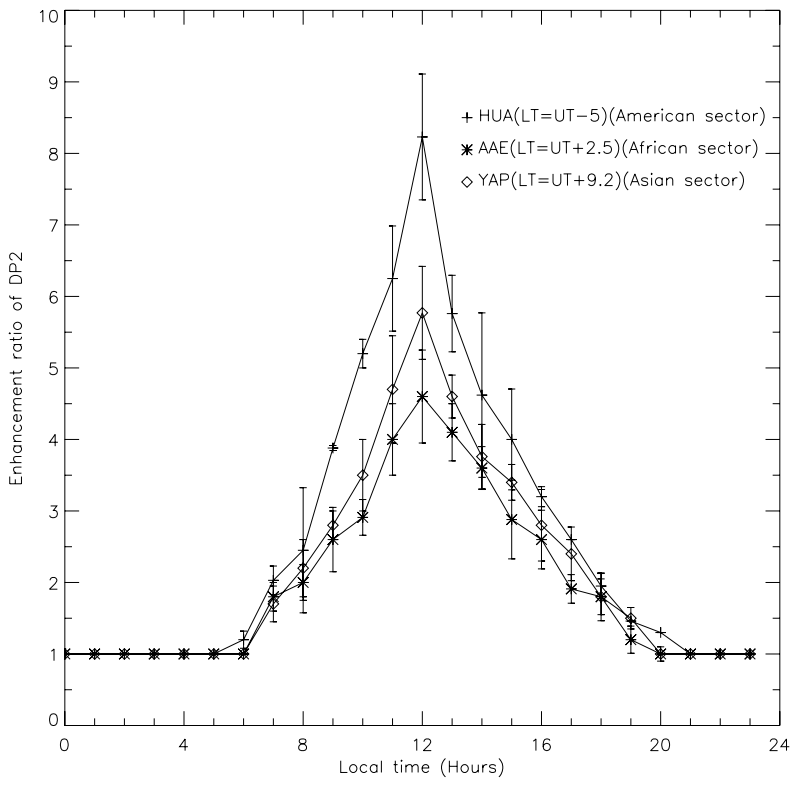

Fig. 7. Results for the year 1998: Diurnal variations of the DP2 enhancement ration average in 1998 at dip-equator compared to low latitude over the American (HUA), African (AAE) and Asian(YAP) sectors.

variations of $\mathrm{H}$ component disturbances (DP) from North polar cap latitudes to dip-equator during these magnetic storms. Over these three sectors, we observe increases of the DP simultaneously at the polar region, middle and low latitudes around 12:00 LT with considerably enhancement at the dipequator According to Nishida (1971), these disturbances are the signature of DP2 events. Table 4 gives the DP2 amplitudes respectively at the low latitude and the equator and the enhancement ratio between the dip-equator and the low latitude over the American, African and Asian longitude sectors for the days 7 October 1998, 10 March 1998 and 19 October 1998, respectively. We note that around the same local time, we have different values of DP2 enhancement ratio over these three longitude sectors. Figure 7 illustrates this result throughout the local time variations of the DP2 enhancement ratio in these three longitude sectors. The Huancayo (HUA) station (American sector) exhibits the highest average value of the DP2 enhancement ratio which peaked up 8 compared to the value of 5.7 of Yap (YAP) station (Asian sector) and 4.5 of Addis Ababa (AAE) station (Asian sector); it is important to note that the AAE station presents the relatively lowest average value. In the same vein, the DP2 enhancement starts early in the morning (05:00 LT) to end in the late afternoon (21:00 LT) over the American sector compared to the African and the Asian sectors where it starts at 06:00 LT and ends at 20:00 LT. The above observations show that the DP2 presents a longitudinal dependence evidenced by the longitudinal variation of the equatorial electroject when we use the average values of the $S_{\mathrm{r}}(H)$ (quiet time reference) observed

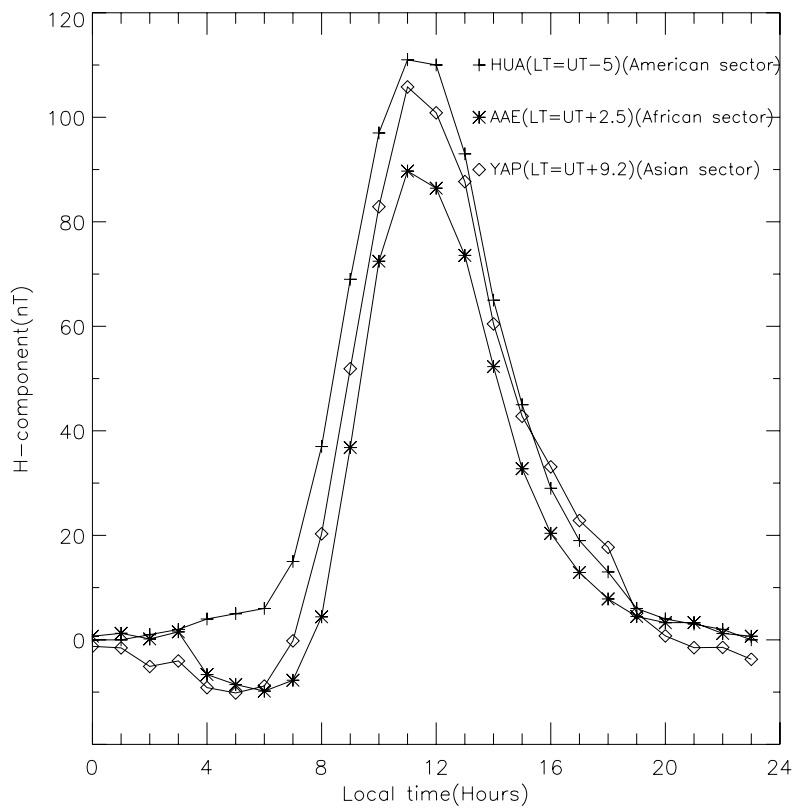

Fig. 8. Regular variation of H-component $\left(S_{\mathrm{r}}(H)\right)$ average of 1998 over the American (HUA), African (AAE) and Asian sectors (YAP).

in 1998 (Fig. 8). The Huancayo station (American sector) exhibits the highest intensity of EEJ compared to those Yap station (Asian sector) and Addis Ababa station (African sector) where the EEJ presents lowest intensity. This longitudinal variation of the EEJ is in accordance to the results obtained by Doumouya et al. (2003). The DP2 enhancement ratio and the EEJ have similar longitudinal dependences.

\section{Conclusion}

The DP2 events are enhanced at the dayside dip-equator compared to low latitude due to the Cowling conductivity effect. The enhancement ratio is characterized by a diurnal variation which is correlated with the regular variation of geomagnetic $\mathrm{H}$ component with a good correlation coefficient of 0.95. This correlation can be used to estimate the DP2 enhancement ratio from the $S_{\mathrm{r}}(H)$ values. The DP2 enhancement ratio at dip-equator and the EEJ presents similar longitudinal variation with the highest values over the American sector compared to those of Asian and African sectors. The African sector exhibits relatively lowest values. Moreover, it is worth to note that over the American sector where the EEJ has a high intensity, the DP2 enhancement starts early in the morning and ends late in the afternoon.

The DP2 enhancement ratio presents a diurnal and longitudinal variations correlated with the equatorial electrojet magnetic effect variations.

Similar studies on other longitude sectors should help in obtaining a good evaluation of these parameters in order to contribute to a better understanding of DP2 events at the 
dip-equator. Such results are useful for the improvement of simulation models of electric field at the dip-equator during the magnetic storms.

Acknowledgements. The authors are grateful to J. O. Adeniyi for his contribution to this paper.

Topical Editor P.-L. Blelly thanks A. D. Richmond and another anonymous referee for their help in evaluating this paper.

\section{References}

Abdu, M. A., Sastri, J. H., Luhr, H., Tachihara, H., and Trivedi Sobral, J. H. A.: DP2 Electric Field Fluctuations in the DuskSide dip-equatorial Ionosphere, J. Geophys. Res. Lett., 25, 15111514, 1998.

Akasofu, S. I.: A source of energy for geomagnetic storms and auroras, Planet. Space Sci., 12, 81-833, 1964.

Baker, W. G. and Martyn, D. F.: Electric currents in the ionosphere, Phil, Trans., Roy. soc., London, A.246, 281-320, 1953.

Block, L. P.: On the distribution of the electric fields in the magnetosphere, J. Geophys. Res., 71, 855-864, 1966.

Cole, K. D.: Magnetic storms and associated phenomena, Space. Sci. Rev., 5, 699-770, 1966.

Doumouya, V., Cohen, Y., Arora, B. R., and Yumoto, K.: Local time and longitude dependence of the equatorial electrojet magnetic effects, J. Atmos.Solar-Terr. Phys., 65, 1265-1282, 2003.

Fambitakoye, O. and Mayaud, P. N.: The equatorial electrojet and regular daily variation $S_{\mathrm{r}}$ : A determination of the equatorial electrojet parameters, J. Atmos. Terr. Phys., 38, 1-17, 1976a.

Fambitakoye, O. and Mayaud, P. N.: The equatorial electrojet and regular daily variation $S_{\mathrm{r}}$ : The centre of the equatorial electrojet, J. Atmos. Terr. Phys., 38, 19-26, 1976 b.

Fejer, B. G.: The electrodynamics of low-latitude ionosphere: Recent results and future challenges, J. Atmos. Terr. Phys., 59, 1465-1482, 1997.

Fejer, B., Spiro, R., Wolf, R. A., and Foster, J.: Latitudinal variations of penetration electric fields during magnetically disturbed periods: 1986 Sundial observations and model results, Ann. Geophys., 8, 441-454, 1990.

Fukushima, N. and Kamide, Y.: Partial ring current models for worldwide geomagnetic disturbances, Rev. Geophys. Space Phys., 11, 795-853, 1973.

Hirono, M.: A theory of diurnal magnetic variation in equatorial regions and conductivity of the ionosphere e region, J. Geomagn. Geoelectr., 4, 5-21, 1952.

Huang, C. S., Sazyking, S., Chauc, J. L., Maruyamad, N., and Kelley, M.: Penetration electric fields: Efficiency and characteristic time scale, J. Atmos. Solar-Terr. Phys., 69, 1135-1146, 2007.

Jaggi, R. K. and Wolf, R. A.: Self-consistent calculation of the motion of a sheet of ions in the magnetosphere, J. Geophys. Res., 78, 2852-2866, 1973.

Karlson, E. T.: Streaming of a plasma through a magnetic dipole field, Phys. Fluids, 6, 708-722, 1963.

Kelley, M. C., Fejer, B. C., and Gonzales, C.: A. An explanation for anomalous equatorial ionospheric electric fields associated with a north ward turning of the interplanetary magnetic field, Geophys. Res. Lett., 6, 301-304, 1979.
Kikuchi, T., Luehr, H., Kitamura, T., Saka, O., and Schlegel, K.: Direct penetration of the polar electric field to the equator during a DP2 event as detected by the auroral and equatorial magnetometer chains and the EISCAT radar, J. Geophys. Res., 101, 17161-17173, 1996.

Kikuchi, T., Luehr, H., Schlegel, K., Tachihara H., Shinohara, M., and Kitamura, T. I.: Penetration of auroral electric fields to the equator during sub-storm, Ann. Geophys., 105, 23251-23261, 2000.

Kikuchi T., Kumiko, K., and Nozaki, K.: Penetretion of magnetospheric electric fields to the equator during a geomagnetic storm, J. Geophys. Res., 113, A06214, doi:10.1029/2007JA012628, 2008.

Kikuchi, T., Ebihara, Y., Hashimoto, K. K., Kataoka, R., Hori, T., Watari, S., and Nishitani, N.: Penetration of the convection and overshielding electric fields to the equatorial ionosphere during a quasi periodic DP2 geomagnetic fluctuation event, J. Geophys. Res., 115, A05209, doi:10.1029/2008JA013948, 2010.

Kobea, A. T., Amory-Mazaudier, C., Do, J. M., Lühr, H., Houngninou, E., Vassal, J., Blanc, E., and Curto, J. J.: Equatorial electrojet as part of the global circuit: a case-study from the IEEY, Ann. Geophys., 16, 698-710, doi:10.1007/s00585-998-0698-1, 1998.

Kobéa, A. T., Richmond, A. D, Emery, B. A., Peymirat, C., Luehr, H., Moretto, T., Hairston, M., and Mazaudier, C. A.: Electrodynamic coupling of high and low latitudes: observations on May 27, 1993, J. Geophys. Res., 105, 22979-22989, 2000.

Nishida, A.: DP 2 and polar substorm, Planet. Space Sci., 19, 205 221, 1971.

Nishida, A., Iwasaki, N., and Nagata, T.: The origin of fluctuations in the equatorial electrojet: A new type of geomagnetic variation, Ann. Geophys., 22, 478-484, 1966.

Nishida, A.: Coherence of geomagnetic DP2 magnetic fluctuations with interplanetary magnetic variations, J. Geophys. Res., 73, 5549-5559, 1968.

Onwumechilli, A., Kawasaki, K., and Akasofu, S.: Relationships between the equatorial electrojet and polar magnetic variations, Planet. Space Sci., 21, 1-13, 1973.

Reddy C. A., Somayajulu, V. V., and Devasia, C. V.: Gobal-scale electrodynamic coupling of the auroral and equatorial dynamo region, J. Atmos. Terr. Phys., 41, 189-201, 1979.

Senior, C. and Blanc, M.: On the control of magnetospheric convection by the spatial distribution of ionospheric conductivities, J. Geophys. Res., 89, 261-284, 1984.

Sobral, J. H. A., Abdu, M. A., Yamashita, C. S., Gonzalez, W. D., Clua de Gonzalez, A., Batista, I. S., Zamlutti, C. J., and Tsurutani, B. T.: Responses of the low-latitude ionosphere to very intense geomagnetic storms, J. Atmos. Sol. Terr. Phys., 63, 965974, 2001.

Southwood, D.: The role of hot plasma in magnetospheric convection, J. Geophys. Res., 82, 5512-5520, 1977.

Spiro, R. W., Wolf, R. A., and Fejer, B. G.: Penetration of high-latitude electric field to low latitude during sundial 1984, Ann. Geophys., 6, 39-50, 1988.

Vasyliunas, V. M.: The interrelationship of magnetospheric process, in 'Earth's Magnetosphere Process', 29-38 pp., D. Reidel, Norwell, Mass, 1972. 